\title{
Crystal Structure and Magnetic Property Studies of a Novel Hybrid Compound $\left(\mathrm{C}_{6} \mathrm{H}_{16} \mathrm{~N}_{2}\right) \mathrm{CoCl}_{4}$
}

\author{
F. Issaoui • Y. Baklouti • E. Dhahri • F. Zouari • \\ M. A. Valente
}

Received: 11 January 2015 / Accepted: 24 February 2015 / Published online: 24 May 2015

(C) Springer Science+Business Media New York 2015

\begin{abstract}
Aminoethyl) pyrrolidinium tetrachlorocobaltat $\left(\mathrm{C}_{6} \mathrm{H}_{16} \mathrm{~N}_{2}\right) \mathrm{CoCl}_{4}$ has been prepared and analyzed by $\mathrm{X}$-ray diffraction. The compound crystallizes in the orthorhombic system with space group $\mathrm{P} 2{ }_{1} 2{ }_{1} 2_{1}$. The unit cell dimensions are $a=7.3279(13), b=13.051(2)$ and $c=13.831(2) \AA$ with $Z=4$. The crystal structure of this salt was solved by Patterson methods and refined by full-matrix least squares on $F^{2}$ to the final values of $R=0.0486$ and $\mathrm{w} R=0.1347$. The structure consists of diprotonated 1-(2aminoethyl) pyrrolidinium cations and monomeric $\mathrm{CoCl}_{4}^{2-}$ These entities are interconnected by means of hydrogen bonding contacts forming a threedimensional network. Magnetization was used to investigate the magnetic properties. This compound exhibits an antiferromagnetic (AFM) to paramagnetic (PM) phase transition at a temperature $\left(T_{\mathrm{N}}\right)$ lower than $2 \mathrm{~K}$. The values of paramagnetic Curie-Weiss temperature $\left(\theta_{\mathrm{cw}}\right)$ and the exchange parameter $\left(J / K_{\mathrm{B}}\right)$ emphasize the existence of an antiferromagnetic interaction between the neighboring cobalt ions.
\end{abstract}

F. Issaoui $(\bowtie) \cdot$ E. Dhahri

Laboratoire de Physique Appliquée, Faculté des Sciences de Sfax, B.P. 1171, 3000 Sfax, Tunisia

e-mail: issawi_fatma@yahoo.fr

Y. Baklouti · F. Zouari

Laboratoire des Sciences des Matériaux et d'Environnement, Faculté des Sciences de Sfax, 3000 Sfax, Tunisia

M. A. Valente

Departamento de Física, Universidade de Aveiro, 3810-193 Aveiro, Portugal
Keywords Synthesis · Crystal structure . Antiferromagnetic

\section{Introduction}

The organic-inorganic hybrid materials based on metal halide units have been the subject of many recent investigations because of their interesting structural and magnetic properties [1-5]. The potential applications of these compounds have drawn the attention of numerous scientists due to their catalysis, bioinorganic, biomimetic and coordination chemistry [6]. They have also played a significant role in the development of the understanding of lowdimensional magnetic systems and, more recently, in semiconducting materials [7]. As known magnetic susceptibility is an important tool for the magnetic characterization of the material. One of the beststudied groups of halide transition-metal complexes, both in solution and the solid state, is the cobalt(II) halide complexes. An extensive study has been performed on magnetic compounds in which the 3-d magnetic ions are tetrahedrally coordinated by the ligand $\left[\mathrm{C}_{6} \mathrm{H}_{18} \mathrm{~N}_{3}\right]$ [8].

An extensive study has been performed on magnetic compounds in which magnetic and thermal behavior of the series of isostructural $\mathrm{N}$-methylmorpholinium compounds $(\mathrm{nmmH})_{2}\left[\mathrm{MX}_{4}\right]$ where $\mathrm{M}=\mathrm{Mn}^{2+}, \mathrm{Co}^{2+}$ or $\mathrm{Cu}^{2+}$ and $\mathrm{X}=\mathrm{Cl}^{-}$or $\mathrm{Br}^{-}[\mathrm{nmmH}=N$-methylmorpholinium]. The compounds are all isomorphous and exhibit weak onedimensional antiferromagnetic interaction, with a contribution from singleion anisotropy in the case of the cobalt complexes [9].

In this paper, we report the preparation, crystal structure and magnetic properties of the compound 1-(2aminoethyl) pyrrolidinium tetrachlorocobaltat. 
Table 1 Summary of intensity data collection and structure refinement

\begin{tabular}{|c|c|}
\hline Empirical formula & {$\left[\mathrm{C}_{6} \mathrm{H}_{16} \mathrm{~N}_{2}\right] \mathrm{CoCl}_{4}$} \\
\hline Formula weight $(\mathrm{g} / \mathrm{mol})$ & 316.94 \\
\hline Crystal size $\left(\mathrm{mm}^{3}\right)$ & $0.24 \times 0.15 \times 0.1$ \\
\hline Crystal system & Orthorhombic \\
\hline Space group & $\mathrm{P} 2{ }_{1} 2_{1} 2_{1}$ \\
\hline$a(\AA)$ & $7.3279(13)$ \\
\hline$b(\AA)$ & $13.051(2)$ \\
\hline$c(\AA)$ & $13.831(2)$ \\
\hline$V\left(\AA^{3}\right)$ & $1322.7(4)$ \\
\hline$Z$ & 4 \\
\hline$D_{\mathrm{x}}\left(\mathrm{g} / \mathrm{cm}^{3}\right)$ & 1.59 \\
\hline$F(000)$ & 644 \\
\hline \multicolumn{2}{|l|}{ Data collection } \\
\hline Diffractometer & BRUKER APEX II CCD \\
\hline Radiation, $\lambda(\AA)$ & 0.71073 \\
\hline$T(\mathrm{~K})$ & 293(2) \\
\hline$\theta$ range $\left(^{\circ}\right)$ & $2.2-25.4$ \\
\hline Index range & $\begin{array}{l}-8 \leq h \leq 3 \\
-15 \leq k \leq 15 \\
-16 \leq l \leq 16\end{array}$ \\
\hline No. of reflections collected & 8517 \\
\hline No. of independent reflections & 2399 \\
\hline Goodness-of-fit on $F^{2}$ & 1.056 \\
\hline$R$ indices $[I>2 \sigma(I)]$ & $\begin{array}{l}\mathrm{R} 1=0.049 \\
\mathrm{wR} 2=0.13\end{array}$ \\
\hline$R$ indices [all data] & $\begin{array}{l}\mathrm{R} 1=0.053 \\
\mathrm{wR} 2=0.135\end{array}$ \\
\hline$(\Delta \rho)_{\max }\left(\mathrm{e} / \AA^{-3}\right)$ & 1.209 \\
\hline$(\Delta \rho)_{\min }\left(\mathrm{e} / \AA^{-3}\right)$ & -0.571 \\
\hline Program system & SHELXL-97 \\
\hline Structure determination & SHELXS-97 \\
\hline
\end{tabular}

\section{Experimental}

\subsection{Crystal Chemistry}

The $\left(\mathrm{C}_{6} \mathrm{H}_{16} \mathrm{~N}_{2}\right) \mathrm{CoCl}_{4}$ crystals were obtained by dissolving in a concentrated $\mathrm{HCl}(36 \%)$ solution a stoichiometric mixture of 1-(2aminoethyl) pyrrolidine and a solution of $\mathrm{CoCl}_{2}$. $6 \mathrm{H}_{2} \mathrm{O}$ in a minimum volume of water. The resulting aqueous solution was left to evaporate slowly at room temperature. After several weeks of evaporation, the product separates as crystals, which were isolated by filtration and dried in air. The new compounds show satisfactory elemental analyses.

\subsection{Crystal Structure}

Intensity data were collected using an Enraf-Nonius Kappa $\mathrm{CCD}$ diffractometer with graphite-monochromator (MoKg, $\lambda=0.71073 \AA$ ). The positional parameters for the heavy atoms were obtained from a three-dimensional Patterson map, while the non- $\mathrm{H}$ atoms were found from successive difference Fourier maps. The structure was refined by fullmatrix least squares using anisotropic temperature factors for all non-hydrogen atoms and the hydrogen atoms were localized and optimized to restraint positions. Calculations were performed with the programs SHELXS and SHELXL [10], using the scattering factors enclosed therein. The crystal data, collected reflections and parameters of the final refinement are reported in Table 1. The final reliability factor converged to $R=0.0486$ and $\mathrm{wR}=0.1347$.

\subsection{Magnetic Measurements}

Magnetic measurements were obtained in the temperature range $2-15 \mathrm{~K}$, with an external magnetic field varying from 0.05 to $5 \mathrm{~T}$.

\section{Results and Discussion}

\subsection{Structure Description}

The final atomic coordinates with $U_{\text {eq }}$ of non-hydrogen atoms are given in Table 2. Interatomic distances, bond angles, and the hydrogen bond scheme are listed in Table 3.

The structure of the title compound consists of isolated monomeric $\left[\mathrm{CoCl}_{4}\right]^{2-}$ and diprotonated 1-(2aminoethyl) pyrrolidinium as shown in Fig. 1 .

An examination of the structure shows that the atomic arrangement can be described by an alternation of organic and inorganic species. The anionic groups are built up of isolated tetrahedral of $\left[\mathrm{CoCl}_{4}\right]^{2-}$ arranged in sandwich between two organic species (Fig. 2).

The anion exhibits tetrahedral geometry, with the $\mathrm{Co}(\mathrm{II})$ ion surrounded by four chlorine atoms, with $\mathrm{Cl}-\mathrm{Co}-\mathrm{Cl}$ angles ranging from $102.78(1)^{\circ}$ to $117.36(8)^{\circ}$. The mean $\mathrm{Co}-\mathrm{Cl}$ bond length, $2.28 \AA$, is close to those observed in similar complex [11, 12].

Generally, the $\mathrm{Co}-\mathrm{Cl}$ bond lengths and $\mathrm{Cl}-\mathrm{Co}-\mathrm{Cl}$ bond angles in the $\left[\mathrm{CoCl}_{4}\right]^{2-}$ anion are not equal to one another, but vary with the environment around the $\mathrm{Cl}$ atoms. In the title compound, the $\mathrm{Co}-\mathrm{Cl}_{1}$ and $\mathrm{Co}-\mathrm{Cl}_{4}$ are obviously longer than $\mathrm{Co}-\mathrm{Cl}_{2}$ and $\mathrm{Co}-\mathrm{Cl}_{3}$. The $\mathrm{Co}-\mathrm{Cl}_{4}$ bond length 230(18) $\AA$ is the longest one and the $\mathrm{Co}-\mathrm{Cl}_{2}$ bond 226(18) $\AA$ the shortest. Owing to the obvious differences in the $\mathrm{Co}-\mathrm{Cl}$ bond lengths and the $\mathrm{Cl}-\mathrm{Co}-\mathrm{Cl}$ angles, the coordination geometry of the Co atom can be regarded as being a distorted tetrahedron.

A projection of the structure in the plane $(b c)$ shows that the organic and inorganic groups alternate, whichever direction is chosen (Fig. 2). In the title compound, the mean plan 
Table 2 Atomic coordinates and $U_{\text {eq }}$ or $U_{\text {iso }}$ for $\left(\mathrm{C}_{6} \mathrm{H}_{16} \mathrm{~N}_{2}\right) \mathrm{CoCl}_{4}$

\begin{tabular}{lllll}
\hline Atoms & $X / a$ & $Y / b$ & $Z / c$ & $U_{\text {eq }}^{a}$ \\
\hline $\mathrm{Co}_{1}$ & $0.61928(11)$ & $0.41283(6)$ & $0.17372(5)$ & $0.0433(2)$ \\
$\mathrm{Cl}_{1}$ & $0.7812(3)$ & $0.33698(15)$ & $0.29411(11)$ & $0.0628(5)$ \\
$\mathrm{Cl}_{2}$ & $0.6397(3)$ & $0.58532(13)$ & $0.18775(15)$ & $0.0737(5)$ \\
$\mathrm{Cl}_{3}$ & $0.7304(3)$ & $0.34080(15)$ & $0.03641(12)$ & $0.0640(5)$ \\
$\mathrm{Cl}_{4}$ & $0.3092(2)$ & $0.38388(12)$ & $0.18607(12)$ & $0.0563(4)$ \\
$\mathrm{C}_{1}$ & $0.4400(12)$ & $0.4897(1)$ & $0.4448(1)$ & $0.081(2)$ \\
$\mathrm{C}_{2}$ & $0.4781(15)$ & $0.4054(11)$ & $0.5067(9)$ & $0.117(4)$ \\
$\mathrm{C}_{3}$ & $0.325(3)$ & $0.3343(10)$ & $0.4909(11)$ & $0.1659(1)$ \\
$\mathrm{C}_{4}$ & $0.1670(15)$ & $0.3973(11)$ & $0.3878(4)$ & $0.122(5)$ \\
$\mathrm{C}_{5}$ & $0.2155(1)$ & $0.5871(4)$ & $0.3215(6)$ & $0.100(3)$ \\
$\mathrm{C}_{6}$ & $0.0722(18)$ & $0.5982(8)$ & $0.3987(4)$ & $0.121(5)$ \\
$\mathrm{N}_{1}$ & $0.2654(9)$ & $0.4784(5)$ & $0.0561(13)$ & $0.0696(18)$ \\
$\mathrm{N}_{2}$ & $0.6893(4)$ & $0.3229(4)$ & \\
\hline
\end{tabular}

${ }^{\mathrm{a}} U_{\mathrm{eq}}=1 / 3 \sum \sum U_{\mathrm{ij}} a_{\mathrm{i}} a_{\mathrm{j}} a_{\mathrm{i}} * a_{\mathrm{j}}$

Table 3 Selected bond $\left(\mathrm{A}^{\circ}\right)$ lengths and angles $\left({ }^{\circ}\right)$ and the hydrogen bonding scheme of $\left(\mathrm{C}_{6} \mathrm{H}_{16} \mathrm{~N}_{2}\right) \mathrm{CoCl}_{4}$

\begin{tabular}{|c|c|c|c|c|}
\hline \multicolumn{2}{|c|}{ Bond lengths $(\AA)$} & \multicolumn{3}{|l|}{ Angles $\left(^{\circ}\right)$} \\
\hline $\mathrm{Co}-\mathrm{Cl}_{1}$ & $2,271(2)$ & $\mathrm{Cl}_{2}-\mathrm{Co}-\mathrm{Cl}_{1}$ & $109,63(8)$ & \\
\hline $\mathrm{CO}-\mathrm{Cl}_{2}$ & $2,264(2)$ & $\mathrm{Cl}_{2}-\mathrm{Co}-\mathrm{Cl}_{3}$ & $117,36(8)$ & \\
\hline $\mathrm{CO}-\mathrm{Cl}_{3}$ & $2,270(2)$ & $\mathrm{Cl}_{1}-\mathrm{Co}-\mathrm{Cl}_{3}$ & $104,20(8)$ & \\
\hline \multirow[t]{3}{*}{$\mathrm{CO}-\mathrm{Cl}_{4}$} & $2,309(2)$ & $\mathrm{Cl}_{2}-\mathrm{Co}-\mathrm{Cl}_{4}$ & $102,78(7)$ & \\
\hline & & $\mathrm{Cl}_{1}-\mathrm{Co}-\mathrm{Cl}_{4}$ & $112,85(7)$ & \\
\hline & & $\mathrm{Cl}_{3}-\mathrm{Co}-\mathrm{Cl}_{4}$ & $110,31(7)$ & \\
\hline $\mathrm{C}_{1}-\mathrm{C}_{2}$ & $1,421(2)$ & $\mathrm{C}_{1}-\mathrm{N}_{1}-\mathrm{C}_{5}$ & $99,6(6)$ & \\
\hline $\mathrm{C}_{1}-\mathrm{N}_{1}$ & $1,437(1)$ & $\mathrm{C}_{1}-\mathrm{N}_{1}-\mathrm{C}_{4}$ & $105,4(7)$ & \\
\hline $\mathrm{C}_{2}-\mathrm{C}_{3}$ & $1,474(2)$ & $\mathrm{C}_{5}-\mathrm{N}_{1}-\mathrm{C}_{4}$ & $127,7(8)$ & \\
\hline $\mathrm{C}_{2}-\mathrm{N}_{2}$ & $1,496(8)$ & $\mathrm{N}_{1}-\mathrm{C}_{4}-\mathrm{C}_{3}$ & $100,7(9)$ & \\
\hline $\mathrm{C}_{3}-\mathrm{C}_{4}$ & $1,50(2)$ & $\mathrm{C}_{2}-\mathrm{C}_{1}-\mathrm{N}_{1}$ & $111,3(8)$ & \\
\hline $\mathrm{C}_{4}-\mathrm{N}_{1}$ & $1,505(1)$ & $\mathrm{C}_{1}-\mathrm{C}_{2}-\mathrm{C}_{3}$ & $104,4(9)$ & \\
\hline $\mathrm{C}_{5}-\mathrm{N}_{1}$ & $1,474(8)$ & $\mathrm{C}_{5}-\mathrm{C}_{6}-\mathrm{N}_{2}$ & $121,9(8)$ & \\
\hline \multirow[t]{2}{*}{$\mathrm{C}_{5}-\mathrm{C}_{6}$} & $1,402(1)$ & $\mathrm{C}_{2}-\mathrm{C}_{3}-\mathrm{C}_{4}$ & $106,8(9)$ & \\
\hline & & $\mathrm{C}_{6}-\mathrm{C}_{5}-\mathrm{N}_{1}$ & $110,6(6)$ & \\
\hline$D-H \ldots A$ & $d(D-H)$ & $d(H . . A)$ & $<D H A$ & $d(D . . A)$ \\
\hline $\mathrm{N}_{1}-\mathrm{H}_{1} \ldots \mathrm{Cl}_{4}$ & 0,910 & 2,297 & 174,89 & 3,205 \\
\hline $\mathrm{N}_{2}-\mathrm{H}_{2} \mathrm{C} \ldots \mathrm{Cl}_{2}^{\mathrm{a}}$ & 0,890 & 2,406 & 154,66 & 3,233 \\
\hline $\mathrm{N}_{2}-\mathrm{H}_{2} \mathrm{D} \ldots \mathrm{Cl}_{1}^{\mathrm{b}}$ & 0,890 & 2,403 & 149,74 & 3,203 \\
\hline $\mathrm{N}_{2}-\mathrm{H}_{2} \mathrm{E} \ldots \mathrm{Cl}_{3}^{\mathrm{c}}$ & 0,890 & 2,391 & 163,64 & 3,254 \\
\hline
\end{tabular}

${ }^{\mathrm{a}}$ Code of symmetry: $\mathrm{x}-1, \mathrm{y}, \mathrm{z}$

${ }^{\mathrm{b}}$ Code of symmetry: $-\mathrm{x}+1, \mathrm{y}+1 / 2,-\mathrm{z}+1 / 2$

${ }^{\mathrm{c}}$ Code of symmetry: $-\mathrm{x}+1 / 2,-\mathrm{y}+1, \mathrm{z}+1 / 2$ 


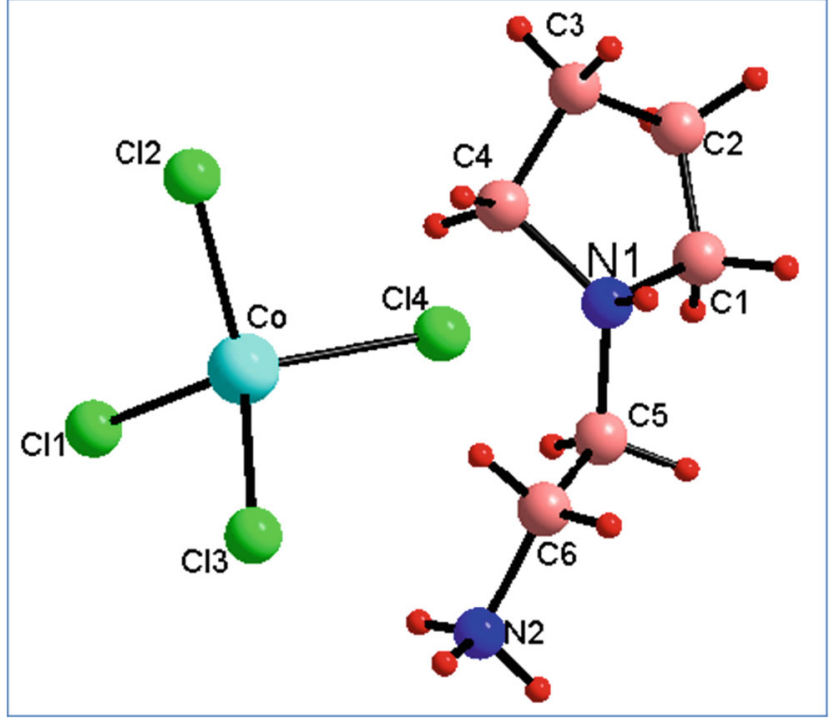

Fig. 1 Atom numbering scheme for the title compound $\left(\mathrm{C}_{6} \mathrm{H}_{16} \mathrm{~N}_{2}\right)$ $\mathrm{CoCl}_{4}$

through the pyrrolidine ring built up by the atoms $\left(\mathrm{N}_{1}, \mathrm{C}_{1}\right.$, $\mathrm{C}_{2}, \mathrm{C}_{3}, \mathrm{C}_{4}$ ) is less planar (r.m.s. deviation $=0.144(1) \mathrm{A}^{\circ}$ ). In fact, the conformation of the ethylamine side chain with respect to pyrrolidine ring is usually described by torsion angles $\mathrm{C}_{1}-\mathrm{N}_{1}-\mathrm{C}_{5}-\mathrm{C}_{6}\left(\tau_{1}\right)$ and $\mathrm{N}_{1}-\mathrm{C}_{5}-\mathrm{C}_{6}-\mathrm{N}_{2}\left(\tau_{2}\right)$. Cation has an extended conformation with $\tau_{1}=164.19(1)$ and $\tau_{2}=156.51(1)$. The $\mathrm{C}-\mathrm{C}$ bond lengths vary from $1.4(11)$ to $1.5(2) \AA$. The $\mathrm{C}-\mathrm{N}$ bond lengths vary from $1.43(11)$ to $1.50(12) \AA$. Table 3 reports the main geometrical features of $\left(\mathrm{C}_{6} \mathrm{H}_{16} \mathrm{~N}_{2}\right)^{2+}$.

In $\left(\mathrm{C}_{6} \mathrm{H}_{16} \mathrm{~N}_{2}\right) \mathrm{CoCl}_{4}$, the organic species interact with the inorganic chains via $\mathrm{N}-\mathrm{H} \sim \mathrm{Cl}$ hydrogen bonds, forming a threedimensional network (Fig. 2). All the hydrogen

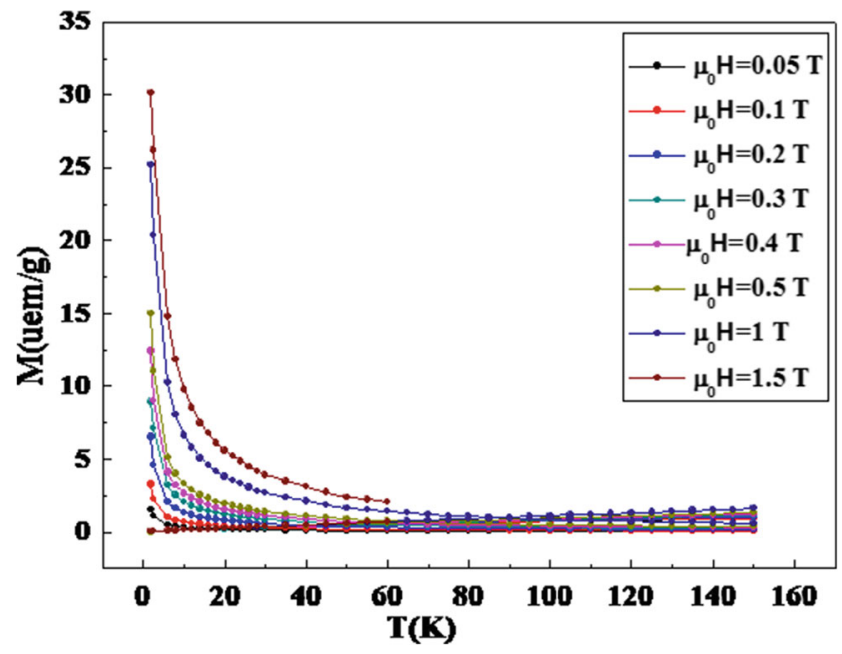

Fig. 3 Variation of the magnetization as a function of temperature for different magnetic fields

bonded to the nitrogen atoms participate in the formation of $(\mathrm{N}-\mathrm{H} \ldots \mathrm{Cl})$ hydrogen bonding with distances 2.297 to $2.406 \AA$. Details of the hydrogen bonding scheme are reported in Table 3.

\subsection{Magnetic Properties}

In Fig. 3, we have plotted the temperature $(T)$ dependence of magnetization $(M)$ for $\left(\mathrm{C}_{6} \mathrm{H}_{16} \mathrm{~N}_{2}\right) \mathrm{CoCl}_{4}$ compound for different applied fields. The increase of magnetization is due to the orientation of spins in the same direction as the applied magnetic field. Note that the thermal evolution of the magnetization has no maximum that shows that the transition ferromagnetic-paramagnetic took place at the Neel
Fig. 2 Projection in the plane $(b c)$ of the atomic arrangement of $\left(\mathrm{C}_{6} \mathrm{H}_{16} \mathrm{~N}_{2}\right) \mathrm{CoCl}_{4}$

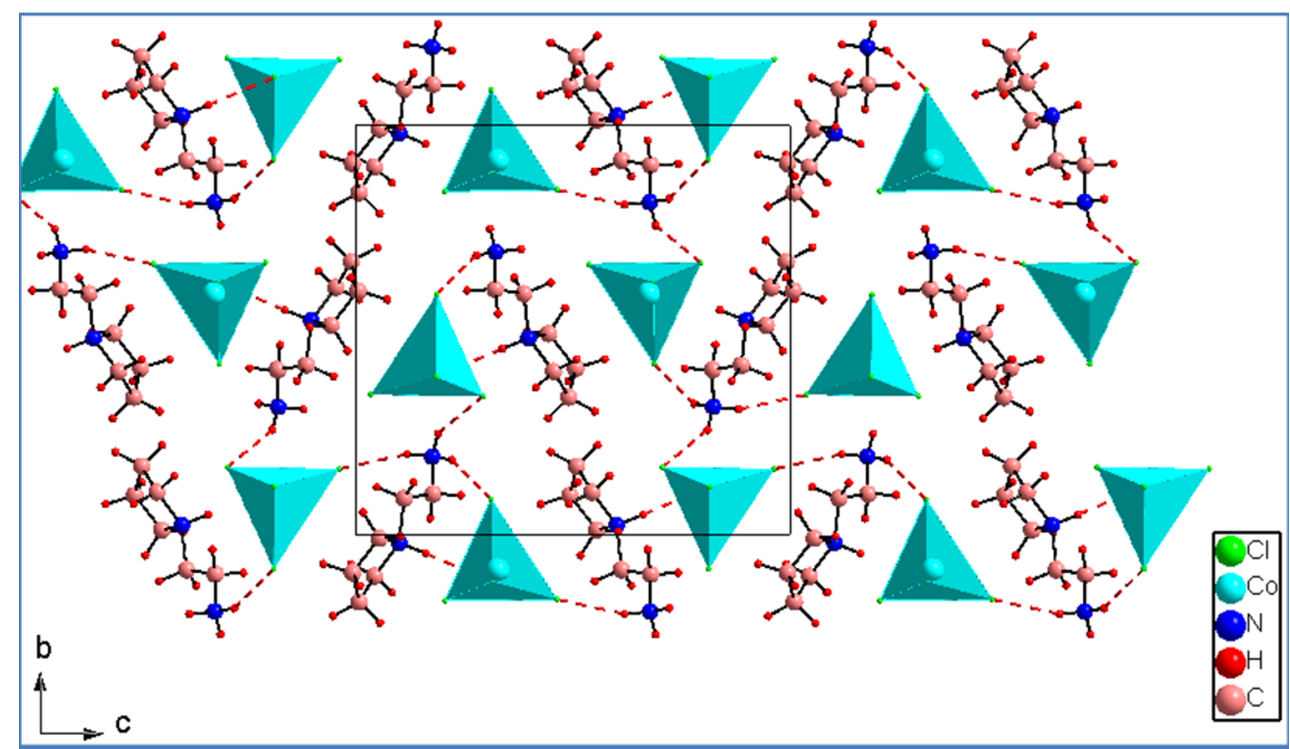



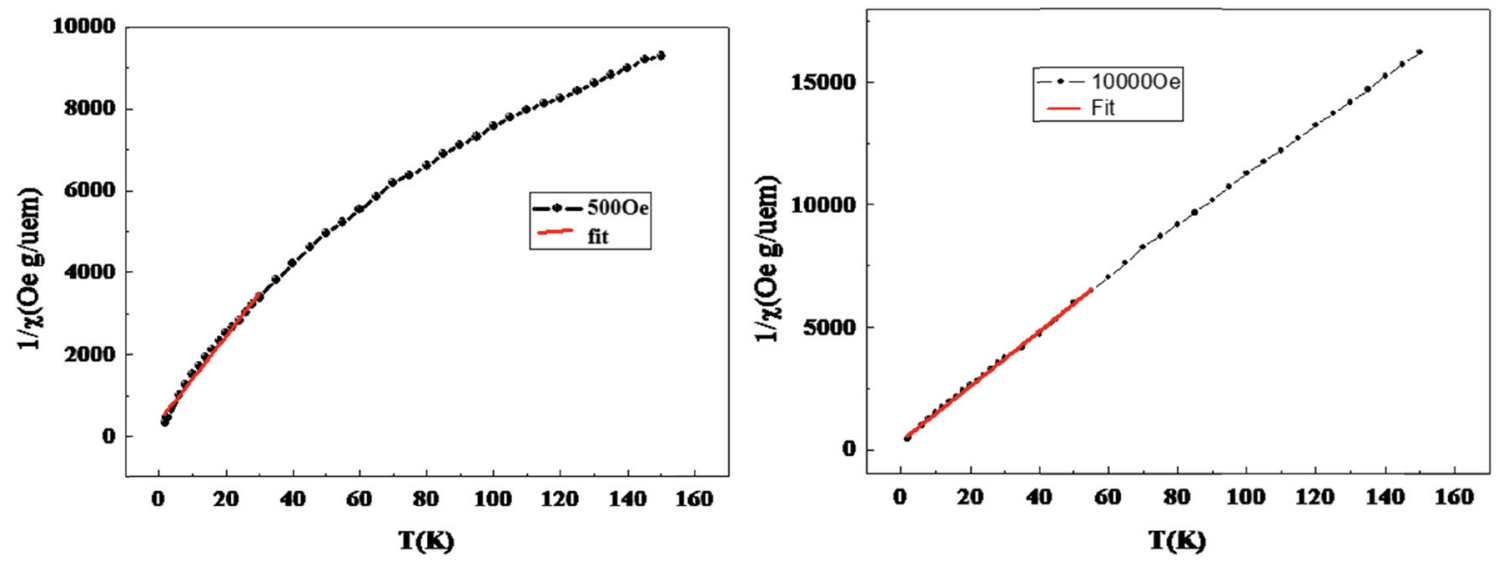

Fig. 4 Temperature dependence of the inverse susceptibility of $\left(\mathrm{C}_{6} \mathrm{H}_{16} \mathrm{~N}_{2}\right) \mathrm{CoCl}_{4}$ as a function of the temperature

temperature $\left(T_{\mathrm{N}}\right)$ lower than $2 \mathrm{~K}$. The magnetic properties are also shown in Fig. 4, in the form of $\frac{1}{\chi}$ versus $T$ plots. The low temperature magnetic susceptibility data was fit to the Curie-Weiss law, given by $\chi=\frac{C}{\left(T-\theta_{\mathrm{cw})}\right.}$. The experimental effective paramagnetic moments $\mu_{\mathrm{eff}}^{\exp }$ were calculated from $C=\left(\frac{N_{\mathrm{A}}}{3 K_{\mathrm{B}}}\right) \mu_{\text {eff }}^{2}$, where $C, \theta_{\mathrm{cw}}, N_{\mathrm{A}}$, $K_{\mathrm{B}}$, and $\mu_{\mathrm{B}}$ have their usual meanings. The values of $C$, $\theta_{\mathrm{cw}}$, and $\mu_{\mathrm{eff}}^{\exp }$ for the applied magnetic fields are deduced from Fig. 4 and are tabulated in Table 4. On the other hand, the theoretical effective moment can be calculated as follows [13]:

$\mu_{\mathrm{eff}}^{\text {the }}=g \mu_{\mathrm{B}} \sqrt{J(J+1)}$;

In our case, according to our sample which contains one unpaired electron $\operatorname{Co}(\mathrm{II})\left(3 \mathrm{~d}^{7}, S=5 / 2\right)$, we found that the value of the effective moment $\left(\mu_{\mathrm{eff}}^{\text {the }}\right)$ is the order of $5.91 \mu_{\mathrm{B}}$. Such a difference between the experimental effective moment and the theoretical one can be explained by the existence of shortrange antiferromagnetic correlations in the paramagnetic state $[14,15]$. The negative temperatures intercept together with the decrease of the effective magnetic moment and are in agreement with the existence of an antiferromagnetic exchange.

Table 4 shows the variation of experimental effective moment as a function of magnetic field. The observed decrease in effective magnetic moment is due to the spinorbit coupling [2] The similar behavior is observed by Issaoui et al. [4]. To investigate other magnetic effects, the

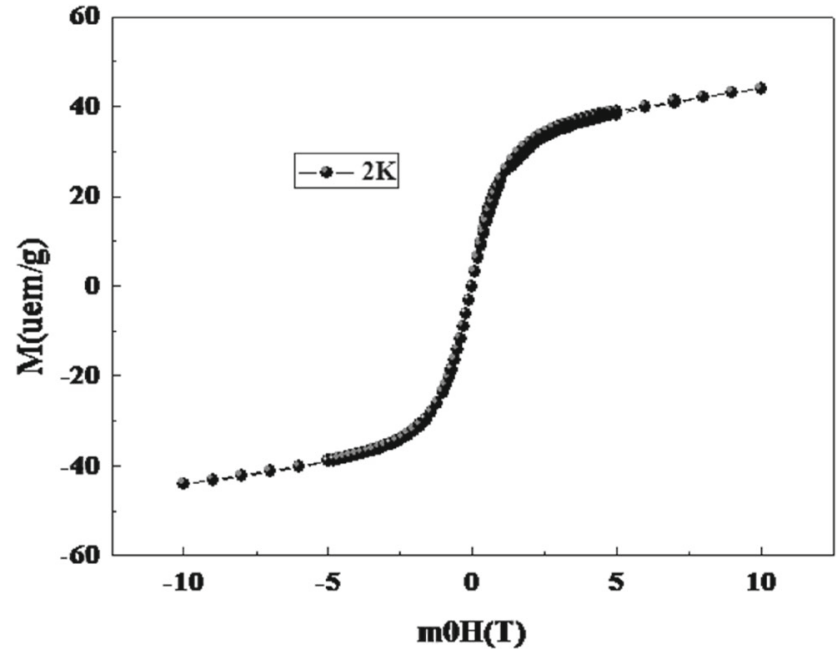

Fig. 5 Hysteresis loops obtained at $2 \mathrm{~K}$ temperature

variation of $M$ vs $\mu_{0} H$ were carried out and the results indicate that the compound possesses a hysteretic behavior (Fig. 5). This hysteresis is consistent with the observed deviation of the Curie-Weiss law (Fig. 4) since a weak ferromagnetic ordering at low temperatures takes place.

Table 5 summarizes the obtained results from the calculation of the exchange parameter $\left(J / k_{\mathrm{B}}\right)$ in order to estimate the order of the exchange interaction between the neighboring cobalt ions using the following equation: $\theta_{\mathrm{cw}}=$ $2 Z(S(S+1)) / 3\left(J / K_{\mathrm{B}}\right)$.

Table 4 Values of the Curie constant, $C$, the Weiss temperature $\theta_{\text {cw }}$, and the experimental magnetic moment $\mu_{\text {eff }}^{\text {exp }}\left(\mathrm{C}_{6} \mathrm{H}_{16} \mathrm{~N}_{2}\right) \mathrm{CoCl}_{4}$

\begin{tabular}{llllllll}
\hline$\mu \mathrm{H}$ & 0.05 & 0.1 & 0.2 & 0.3 & 0.4 & 0.5 & 1 \\
\hline$C$ & 3.03 & 2.93 & 2.92 & 2.9 & 2.89 & 2.88 \\
$\theta_{\mathrm{cw}}$ & -3.36 & -3.32 & -3.3 & -3.05 & -3.01 & -2.95 \\
$\mu_{\text {eff }}$ & 4.92 & 4.89 & 4.85 & 4.84 & 4.81 & 4.80 & -2.91 \\
\hline
\end{tabular}


Table 5 Variation of the exchange parameter in $\left(\mathrm{C}_{6} \mathrm{H}_{16} \mathrm{~N}_{2}\right) \mathrm{CoCl}_{4}$ with applied magnetic field

\begin{tabular}{llllllll}
\hline$\mu \mathrm{H}$ & 0.05 & 0.1 & 0.2 & 0.3 & 0.4 & 0.5 & 1 \\
\hline$J / K_{\mathrm{B}}$ & -446 & -4.51 & -4.54 & -4.91 & -4.98 & -5.08 & -5.15 \\
\hline
\end{tabular}

The large values of $J / k_{\mathrm{B}}$ are suggestive of an antiferromagnetically coupled system with an $S=3 / 2$ ground state between the neighboring cobalt ions as expected from the $1 / \chi$ versus $T$ plots as well as from the structural data.

\section{Conclusion}

Treatment of 1-(2aminoethyl) pyrrolidine $\left(\mathrm{C}_{6} \mathrm{H}_{14} \mathrm{~N}_{2}\right)$ with $\mathrm{CoCl}_{2} \cdot 6 \mathrm{H}_{2} \mathrm{O}$ in aqueous solution gives the organicinorganic hybrid ionic compound $\left(\mathrm{C}_{6} \mathrm{H}_{16} \mathrm{~N}_{2}\right) \mathrm{CoCl}_{4}$ The asymmetric unit of $\left(\mathrm{C}_{6} \mathrm{H}_{16} \mathrm{~N}_{2}\right) \mathrm{CoCl}_{4}$ is constituted by isolated monomeric tetrachloro cobaltat(II) and independent 1-(2aminoethyl) pyrrolidinium cations linked via $\mathrm{N}-\mathrm{H}$. . . Cl hydrogen bonds. The compound crystallizes at room temperature in the orthorhombic space group $\mathrm{P} 2{ }_{1} 2_{1} 2_{1}$.

Magnetic measurements revealed that the thermal variation of the magnetic susceptibility exhibited an antiferromagnetic interaction between the $\mathrm{Co}$ (II) centers which has been confirmed by the values of the exchange parameter. The isothermal magnetization curves with the absence of magnetic hysteresis loops proved the perfect magnetic reversibility of $\left(\mathrm{C}_{6} \mathrm{H}_{16} \mathrm{~N}_{2}\right) \mathrm{CoCl}_{4}$ compound.

\section{References}

1. Long, G.S., Wei, M., Willett, R.D.: Inorg. Chem. 36(14), 31023107 (1997)

2. Baccar, I., Issaoui, F., Zouari, F., Hussein, M., Dhahri, E., Valente, M.A.: Solid State Commun. 150, 2005-2010 (2010)

3. Parent, A.R., Landee, C.P., Turnbull, M.M.: Inorg. Chim. Acta 360, 1943-1953 (2007)

4. Issaoui, F., Baccar, I., Dhahri, E., El Sadek, O., Zouari, F., Hlil, E.K.: J. Supercond. Nov. Magn. 25, 1563-1570 (2012)

5. Luque, A., Sertucha, J., Castillo, O., Román, P.: Polyhedron 21, 19-26 (2002)

6. Ciampolini, M., Nardi, N., Vantacoli, B., Micheloni, M.: Coord. Chem. Rev. 120, 223 (1992)

7. Mitzi, D.B.: Prog. Inorg. Chem. 48, 1-4 (1999). and references therein

8. Carlin, R.L.: J. Am. Chem. Soc. 83, 3773 (1961)

9. Parent, A.R., Landee, C.P., Turnbull, M.M.: Inorg. Chim. Acta 360, 1943-1953 (2007)

10. Sheldrick, G.M.: Acta Crystallogr. Sect. A 64, 112 (2008)

11. Jebas, S.R., Balasubramanian, T., Light, M.E.: Acta Crystallogr. E 62, m1818-m1819 (2006)

12. Zhang, H., Fang, L., Yuan, R.: Acta Crystallogr. E 61, m677m678 (2005)

13. Kittel, C. Introduction to Solid State Physics, 6th, pp. 404-406. Wiley, New York (1985)

14. Terashita, H., Neumeier, J.J.: Phys. Rev. B 71, 134 (2005)

15. Zemni, S., Gasmi, A., Boudard, M., Oumezzine, M.: Mater. Sci. Eng. B 144, 117 (2007) 